Corresponding author:wkc15@ columbia.edu

(C) 2015 Yang et al. This article is distributed under the terms of the Creative Commons Attribution-NonCommercial License, which permits reuse and redistribution, except for commercial purposes, provided that the original author and source are credited.

Ontology terms: central hypotonia; intellectual disability, severe; severe global developmental delay

Published by Cold Spring Harbor Laboratory Press

doi: $10.1101 / \mathrm{mcs} . a 000562$

\section{De novo truncating variants in the AHDC1 gene encoding the AT-hook DNA-binding motif-containing protein 1 are associated with intellectual disability and developmental delay}

\author{
Hui Yang, ${ }^{1}$ Ganka Douglas, ${ }^{1}$ Kristin G. Monaghan, ${ }^{1}$ Kyle Retterer, ${ }^{1}$ Megan T. Cho, ${ }^{1}$ \\ Luis F. Escobar, ${ }^{2}$ Megan E. Tucker, ${ }^{2}$ Joan Stoler, ${ }^{3}$ Lance H. Rodan, ${ }^{3}$ Diane Stein, ${ }^{4}$ \\ Warren Marks, ${ }^{5}$ Gregory M. Enns, ${ }^{6}$ Julia Platt, ${ }^{6}$ Rachel Cox, ${ }^{6}$ Patricia G. Wheeler, ${ }^{7}$ \\ Carrie Crain, ${ }^{7}$ Amy Calhoun, ${ }^{8}$ Rebecca Tryon, ${ }^{8}$ Gabriele Richard, ${ }^{1}$ Patrik Vitazka, ${ }^{1}$ \\ and Wendy K. Chung 9

\begin{abstract}
${ }^{1}$ GeneDx, Gaithersburg, Maryland 20877, USA; ${ }^{2}$ Peyton Manning Children's Hospital at St. Vincent, Indianapolis, Indiana 46260, USA; ${ }^{3}$ Division of Genetics and Genomics, Boston Children's Hospital, Boston, Massachusetts 02115, USA; ${ }^{4}$ Stein Life Child Neurology, Irvine, California 92604, USA; ${ }^{5}$ Cook Children's Medical Center, Fort Worth, Texas 76104, USA; ${ }^{6}$ Division of Medical Genetics, Lucile Packard Children's Hospital Stanford, Palo Alto, California 94304, USA; ${ }^{7}$ Nemours Children's Hospital, Orlando, Florida 32827, USA; ${ }^{8}$ University of Minnesota Medical Center, Minneapolis, Minnesota 55454, USA; ${ }^{9}$ Departments of
\end{abstract} \\ Pediatrics and Medicine, Columbia University Medical Center, New York, New York 10032, USA
}

Abstract Whole-exome sequencing (WES) represents a significant breakthrough in clinical genetics, and identifies a genetic etiology in up to $30 \%$ of cases of intellectual disability (ID). Using WES, we identified seven unrelated patients with a similar clinical phenotype of severe intellectual disability or neurodevelopmental delay who were all heterozygous for de novo truncating variants in the AT-hook DNA-binding motif-containing protein 1 (AHDC1). The patients were all minimally verbal or nonverbal and had variable neurological problems including spastic quadriplegia, ataxia, nystagmus, seizures, autism, and self-injurious behaviors. Additional common clinical features include dysmorphic facial features and feeding difficulties associated with failure to thrive and short stature. The AHDC1 gene has only one coding exon, and the protein contains conserved regions including AT-hook motifs and a PDZ binding domain. We postulate that all seven variants detected in these patients result in a truncated protein missing critical functional domains, disrupting interactions with other proteins important for brain development. Our study demonstrates that truncating variants in AHDC1 are associated with ID and are primarily associated with a neurodevelopmental phenotype.

[Supplemental material is available for this article.]

\section{INTRODUCTION}

Intellectual disability (ID) is present in 3\% of children (Petersen et al. 1998; Shevell et al. 2003; Michelson et al. 2011). Up to 50\% of moderate-to-severe ID cases are due to genetic causes (McLaren and Bryson 1987). Cytogenetically detectable chromosome aberrations account for almost $15 \%$ of cases (Leonard and Wen 2002). X-linked genetic defects are estimated 
COLD SPRING HARBOR Molecular Case Studies
AHDC1 is associated with intellectual disability to account for $\sim 10 \%$ of males with ID (Ropers 2010) and associated with more than 100 X-linked genes (Musante and Ropers 2014). Autosomal-dominant de novo mutations have been found as an important cause of ID in sporadic patients and have a low recurrence risk (Veltman and Brunner 2012), whereas the role of inherited variants in unaffected parents is less well understood. However, autosomal-recessive ID has a high recurrence risk and is the most common type of ID in consanguineous families (Musante and Ropers 2014), although only approximately 30 loci and 10 genes have been identified to date (Afroze and Chaudhry 2013). During the past decade, significant progress has been made to elucidate the genetic causes of ID. However, up to $60 \%$ of individuals with ID still do not have an identified etiology (Rauch et al. 2006). The FORGE (Finding of Rare Disease Genes) Canada Consortium project has identified disease-causing variants for 146 rare disorders including ID (Beaulieu et al. 2014). The Deciphering Developmental Disorders (DDD) study is also trying to identify the genetic causes for ID and other related developmental disorders and has recruited more than 12,600 families from the United Kingdom and Ireland for genomic analyses.

Genetic evaluation of ID routinely includes a chromosomal analysis/microarray and fragile X testing (Michelson et al. 2011; Flore and Milunsky 2012). If this initial diagnostic workup is unrevealing and if there are no specific clinical features to suggest a diagnosis, wholeexome sequencing (WES) is increasingly utilized as the next diagnostic test because of the tremendous genetic heterogeneity and incomplete knowledge of all the genes causing ID (Yang et al. 2013, 2014), The yield of WES for patients with ID is $27 \%-33 \%$ in large clinical series (Yang et al. 2013, 2014).

Here we describe novel truncating de novo variants in the AHDC1 gene associated with ID, identified using WES. AHDC1, located on Chromosome 1p36.11, encodes the 1603 amino acid protein AT-hook DNA-binding motif-containing protein 1. AHDC1 has previously been implicated as a rare cause of ID (Xia et al. 2014), and all five published variants are in the coding exon. Four de novo truncating mutations are associated with syndromic expressive language delay, hypotonia, and sleep apnea (Xia et al. 2014). A de novo missense variant was identified in 1 out of 53 sporadic cases of schizophrenia by exome sequencing (Guipponi et al. 2014). Recently, a de novo balanced translocation with a breakpoint in AHDC 1 intron 1 that disrupts the 5' untranslated region of AHDC1 was identified in a 5-yrold boy with developmental delay and ID (Quintero-Rivera et al. 2015). To better understand the association of AHDC1 with ID and characterize the clinical phenotype of this new syndrome, we report our findings of de novo variants in seven patients from unrelated families with a similar clinical phenotype of severe intellectual disability or neurodevelopmental delay.

\section{RESULTS}

Exome sequencing was performed on 2157 cases with ID or developmental delay. From these cases, there were seven proband-parent trios with de novo AHDC1 variants. These seven cases produced an average of $\sim 9.5 \mathrm{~Gb}$ of sequence per sample. Mean coverage of captured regions was $\sim 115 \times$ per sample, with $>97 \%$ covered with at least $10 \times$ coverage, an average of $>92 \%$ of base call quality of $\mathrm{Q} 30$ or greater, and an overall average mean quality score of >035 (Supplemental Table 1). Initial filtering identified 271 genes (382 unique sequence changes) of interest across the seven families when considering all possible modes of inheritance. After manual filtering of variants with a minor allele frequency of $>1 \%$ in reference populations, known disease association, pattern of inheritance, and similarity of clinical phenotype, there was one common gene of interest. In each case AHDC1 was the leading candidate because there was a novel, de novo loss of function variant, and loss of function alleles were absent from any public population database (6000 individuals of European and African American ancestry from the NHLBI Exome Variant Server), the 
Database of Single Nucleotide Polymorphisms (dbSNP), as well as our internal database including more than 6000 exomes of reportedly unaffected individuals. Only one nonsense variant p.Arg925Ter, located at Chr1: 27875854 G>A, has been seen in 1 out of 65,748 alleles in Exome Aggregation Consortium (ExAC), but with a low GQ score of $~ 40$, suggesting that this may not be present. Other variants in other genes were eliminated from consideration because there was a single variant in a gene observed in asymptomatic parents or because it was de novo but not predicted to alter protein function.

All seven de novo AHDC1 variants are either novel frameshift or nonsense variants that are predicted to result in loss of protein function (Table 1). The seven patients from unrelated families range in age from 2 to $16 \mathrm{yr}$ and have multiple neurobehavioral manifestations. All have significant developmental delay or intellectual disability and are either nonverbal or had limited ability for verbal expressive language (Table 1). Exact developmental quotient/intelligence quotients were not consistently determined with the same instruments, but the degree of impairment ranged from moderate to severe, based on standardized age appropriate measures of intelligence. All of the patients demonstrate problems with muscle tone and global developmental delays, with the age at walking ranging from 20 mo to $4 \mathrm{yr} 9 \mathrm{mo}$. Five of the patients have ataxia. The majority of the patients have behavioral issues. Two patients have autism (based on clinical diagnosis using DSM IV or V criteria), two have self-injurious behavior, one is impulsive, one is aggressive, and one patient is described as being very affectionate. Four of the children have problems with sleep: one with sleep apnea, one a "restless sleeper," one with trouble staying asleep, and another with trouble falling and staying asleep. One patient had two seizures that were not captured on EEG and another had an abnormal EEG with epileptiform activity. MRIs of the brain were abnormal in five patients, three of whom had a small or thin corpus callosum.

In addition to the neurobehavioral features, there are other clinical manifestations. Six patients have dysmorphic facial features including bitemporal hollowing, brachycephaly, plagiocephaly, short nose, narrow mouth, highly arched palate, tented upper lip, and high, prominent forehead with prominent glabella (Fig. 1). Five patients had a history of growth problems including short stature or failure to thrive and feeding difficulties. Two of the patients have joint laxity. Five patients have ophthalmologic problems, including one with cupped optic disks with unilateral central macular dystrophy and nystagmus, one with nystagmus only, two with strabismus only, and one with nystagmus along with strabismus and cortical visual impairment.

\section{DISCUSSION}

Seven proband-parent trios with de novo AHDC1 variants were identified through wholeexome sequencing on 2157 cases with ID or developmental delay. The seven patients from unrelated families with a similar clinical phenotype of severe intellectual disability or neurodevelopmental delay, dysmorphic features, and problems with feeding and growth were all found to be heterozygous for novel de novo truncating variants in AHDC1. We report six novel predicted deleterious variants and one recurrent variant, (p.Cys791Trpfs*57), which was previously reported in two patients by Xia et al. (2014). Xia et al. has proposed that AHDC1-associated ID is due to a dominant-negative mechanism given the autosomal-dominant inheritance and the single coding exon of this gene. However, a de novo balanced translocation with a breakpoint in AHDC1 intron 1 that disrupts the 5'UTR of AHDC1 has been identified in a 5-yr-old male patient with developmental delay and ID (QuinteroRivera et al. 2015). AHDC1 expression in lymphoblastoid cells was found to be reduced to $50 \%$ of wild-type levels, supporting haploinsufficiency as disease mechanism for AHDC1 mutations (Quintero-Rivera et al. 2015). Additionally, several large CNV deletions that 


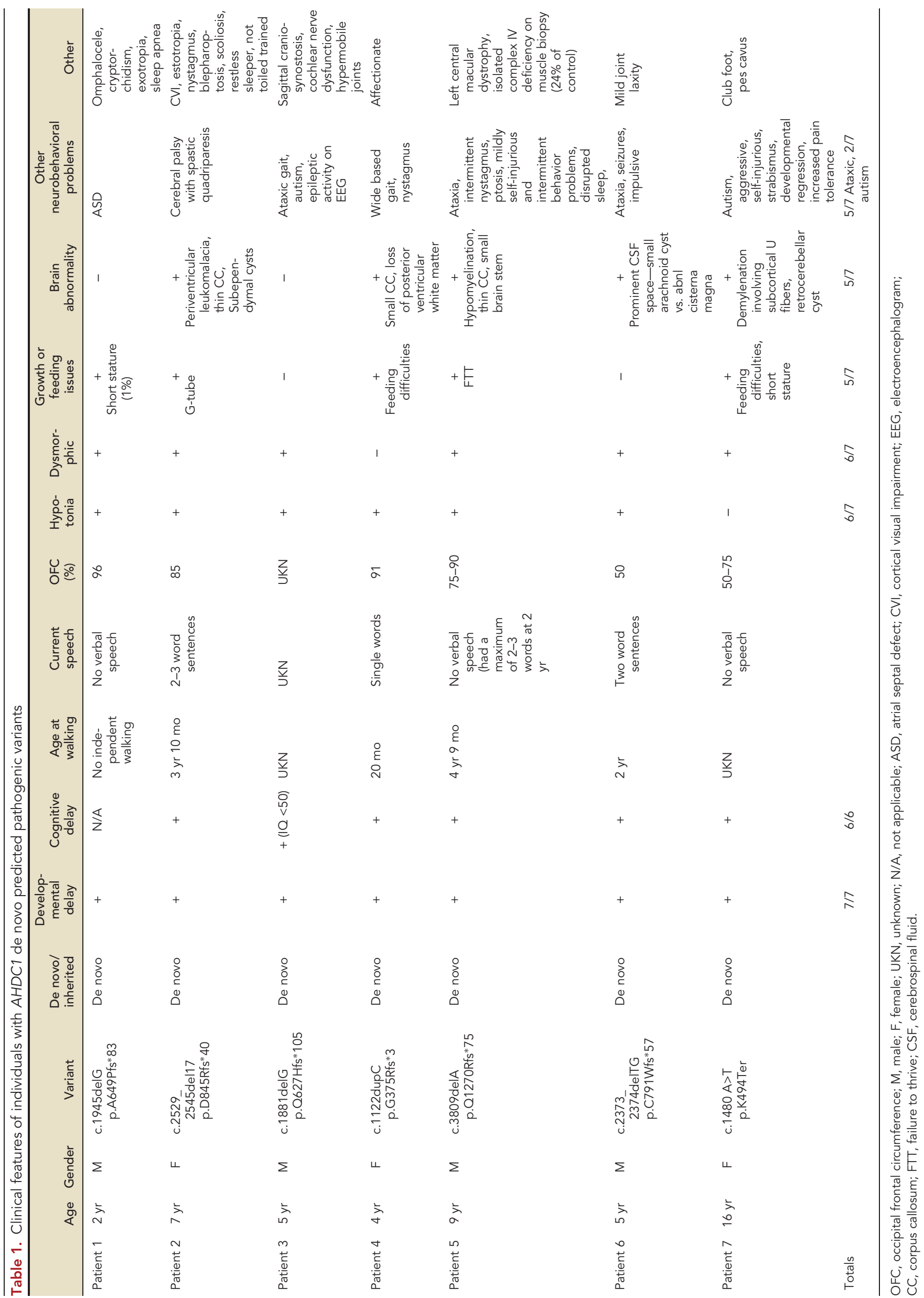


Figure 1. Facial characteristics of individuals with AHDC1 variants including a high, broad prominent forehead, hypertelorism, depressed nasal bridge, and thin upper lip.

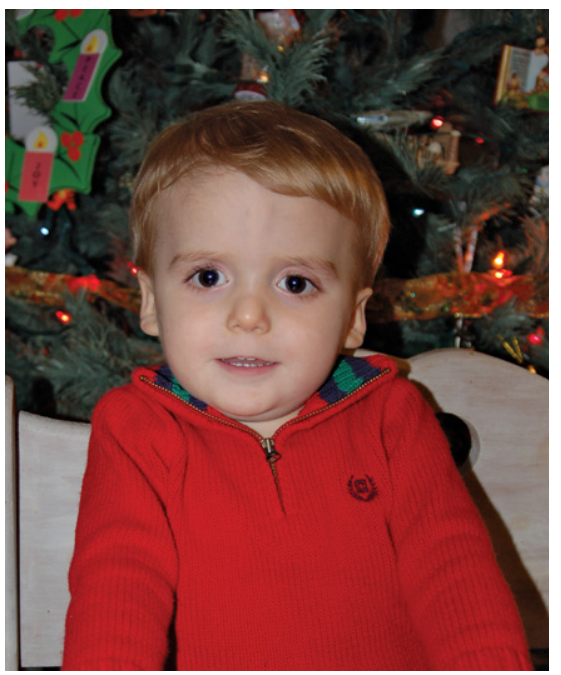

include the AHDC1 gene have been described in pediatric patients with developmental delay and intellectual disability (Itsara et al. 2009; Cooper et al. 2011; Coe et al. 2014). However, due to the large size of the deletions, it is uncertain whether AHDC1 is the only gene contributing to the neurodevelopmental phenotype.

AHDC1 consists of seven exons with only one coding exon (exon 6). Five $5^{\prime}$ noncoding exons and one $3^{\prime}$ noncoding exon flank the coding exon. AHDC1 encodes the 1603 amino acid protein AT-hook DNA-binding motif-containing protein 1, which likely binds DNA (Fig. 2; Reeves and Nissen 1990). By aligning human AHDC1 to other protein orthologs, two conserved regions have been reported in AHDC1 (Xia et al. 2014). The first conserved region has two AT-hook motifs located at amino acids $396-408$ and 544-556. AT-hook motifs are known as auxiliary protein motifs that cooperate with other DNA-binding activities and facilitate DNA structure changes (Aravind and Landsman 1998). The AT-hook binding domain in MECP2, the gene mutated in Rett syndrome, plays an important role in chromatin organization (Baker et al. 2013; Xu and Pozzo-Miller 2013). The second conserved region near the carboxyl terminus contains a carboxy-terminal PDZ binding domain consensus sequence that interacts with PDZ domain proteins (Shalaby et al. 2011). PDZ domain proteins regulate multiple biological processes such as transport of electrolyte and fluid (Seidler et al. 2009), ion channel signaling, and signal transduction systems by recognizing short amino acid motifs at the carboxyl termini of target proteins (Lee and Zheng 2010).

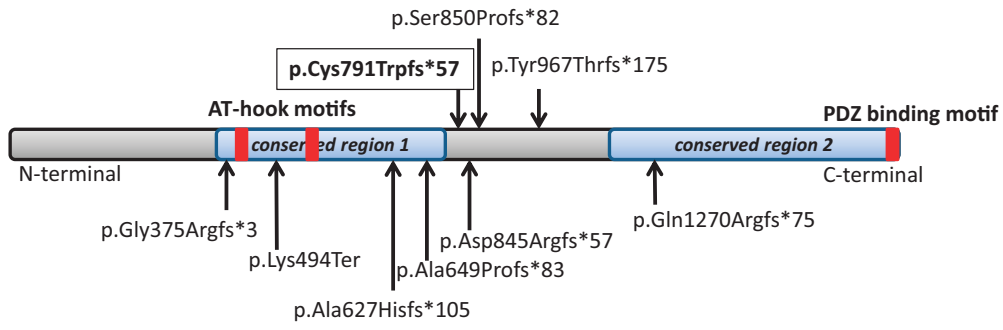

Figure 2. $A H D C 1$ gene organization and distribution of truncating mutations. $A H D C 1$ consists of seven exons with only one coding (exon 6). Three mutations above the schematic protein were reported by Xia et al. (2014). Six mutations below the schematic protein are novel mutations reported in this study. The mutation in the box reported by Xia et al. was found in one of our probands. 
COLD SPRING HARBOR Molecular Case Studies
AHDC1 is associated with intellectual disability
The in vivo targets for AHDC1 binding are largely unknown. However, in vitro assays demonstrate that AHDC1 interacts with a number of other nuclear proteins (Chatr-Aryamontri et al. 2015), influencing transcriptional and epigenetic regulation during development (Lim et al. 2006; Vandamme et al. 2011), receptors in neurite growth, neuronal adhesion, and axonogenesis (Olah et al. 2011), and transporters for specific neuron proteins (Butland et al. 2014). AHDC1 is expressed throughout the brain (Ponten et al. 2008; Uhlen et al. 2015). In the mouse, Ahdc1 is expressed at embryonic day E11.5 and E16.5 in the developing brain (Quintero-Rivera et al. 2015), suggesting that AHDC1 may be involved in early brain development.

Four of our de novo AHDC1 variants and three previously reported variants (Xia et al. 2014) are predicted to cause protein truncation beyond the AT-hook motifs and to eliminate the PDZ binding domain consensus sequence. The other two remaining de novo AHDC1 variants (p.Lys494Ter and p.Gly375Argfs*3) lead to an even earlier stop of translation thus destroying both of the conserved regions. As these truncating variants are all located in the single coding exon of AHDC1, they may not result in nonsense mediated mRNA decay (Schoenberg and Maquat 2012). Although we did not conduct expression studies in our cohort, based on these observations, we speculate that AHDC1 variants may interrupt protein translation, leading to truncated proteins missing the functional domains, possibly disrupting the interaction with other proteins, such as PDZ domain proteins important to brain development and function. The phenotype in all seven patients we report is dominated by neurobehavioral manifestations including ID, autism spectrum disorder, sleep disturbances, gross motor delays, and ataxia, but also includes facial dysmorphism. Our series expands the phenotype of AHDC1 disorders to include behavioral phenotypes of aggression, self-injurious behavior. Other medical features include problems with growth, epilepsy, nystagmus, omphalocele, and clubfoot.

WES has become an important diagnostic tool to evaluate patients with developmental delay and ID, especially in patients with nonspecific clinical features. Our study demonstrates that truncating de novo variants in AHDC1 are a rare cause of severe ID and are associated with feeding difficulties and problems with growth, and a neurobehavioral phenotype is emerging that includes challenging behaviors such as self-injury, aggression, autism, ataxia, and disordered sleep. Variants in AHDC1 should be further investigated in patients with this neurobehavioral profile.

\section{METHODS}

\section{Whole-Exome Sequencing}

Genomic DNA from whole blood from the affected children and their parents was extracted. Exome sequencing was performed on exon targets isolated by capture using the Agilent SureSelect Human All Exon V4 (50 Mb) kit (Agilent Technologies). One microgram of DNA from blood specimen was sheared into 350- to 400-bp fragments, which were then repaired, ligated to adaptors, and purified for subsequent PCR amplification. Amplified products were then captured by biotinylated RNA library baits in solution following the manufacturer's instructions. Bound DNA was isolated with streptavidin-coated beads and re-amplified. The final isolated products were sequenced using the Illumina HiSeq 2000/2500 sequencing system with 100-bp paired-end reads (Illumina). DNA sequence was mapped to the published human genome build UCSC hg19/GRCh37 reference sequence. Targeted coding exons and splice junctions of known protein-coding RefSeq genes were assessed for average depth of coverage with a minimum depth of $10 \times$ required for inclusion in downstream analysis. Local realignment around insertion-deletion sites was performed using the Genome Analysis Toolkit v1.6. (DePristo et al. 2011). Variant calls were generated 
COLD SPRING HARBOR Molecular Case Studies
AHDC1 is associated with intellectual disability simultaneously on all sequenced family members using SAMtools v0.1.18. (Li et al. 2009). All coding exons and surrounding intron/exon boundaries were analyzed. Automated filtering removed common sequence changes (defined as $>10 \%$ frequency present in 1000 Genomes database) and additional filtering focused on variants with an allele frequency $<1 \%$. The targeted coding exons and splice junctions of the known protein-coding RefSeq genes were assessed for the average depth of coverage and data quality threshold values. Whole-exome sequence data for all sequenced family members were analyzed using GeneDx's XomeAnalyzer (a variant annotation, filtering, and viewing interface for WES data), which includes nucleotide and amino acid annotations, population frequencies (NHLBI Exome Variant Server and 1000 Genomes databases), in silico prediction tools, amino acid conservation scores, and mutation references. Variants were filtered based on inheritance patterns, gene lists of interest, phenotypes, and population frequencies, as appropriate. Resources including the Human Gene Mutation Database (HGMD), 1000 Genomes database, NHLBI Exome Variant Server, OMIM, PubMed and ClinVar were used to evaluate genes and detected sequence changes of interest. The general assertion criteria for variant classification are publicly available on the GeneDx ClinVar submission page (http://www.ncbi .nlm.nih.gov/clinvar/submitters/26957/). Additional searches were performed using specific gene lists related to clinical features of the patients. Identified sequence changes of interest were confirmed in all family members by conventional di-deoxy DNA sequence analysis using an ABI 3730 (Life Technologies) and standard protocols with a new DNA preparation.

\section{ADDITIONAL INFORMATION}

\section{Ethics Statement}

The study was approved by the Institutional Review Board of Columbia University and written consent was obtained for collecting blood samples and sequencing from all study participants.

\section{Database Deposition and Access}

Whole-exome sequencing data is not publicly available because patient consent could not be obtained. The AHDC1 variants have been deposited in ClinVar (http://www.ncbi.nlm.nih. gov/clinvar/) under accession numbers SCV000243809-SCV000243815.

\section{Acknowledgments}

We thank the families for their generous contributions.

\section{Author Contributions}

H.Y. analyzed the data, drafted and critically reviewed the manuscript. G.D. analyzed the data and critically reviewed the manuscript. K.G.M. analyzed the data and critically reviewed the manuscript. K.R. generated and analyzed the data and critically reviewed the manuscript. M.T.C. analyzed the data and critically reviewed the manuscript. L.F.E. provided the clinical data and critically reviewed the manuscript. M.E.T. provided the clinical data and critically reviewed the manuscript. J.S. provided the clinical data and critically reviewed the manuscript. L.H.R. provided the clinical data and critically reviewed the manuscript. D.S. provided the clinical data and critically reviewed the manuscript. W.M. provided the clinical data and critically reviewed the manuscript. G.E. provided the clinical data and critically reviewed the manuscript. J.P. provided the clinical data and critically reviewed the manuscript. R.C. provided the clinical data and critically reviewed the manuscript. P.G.W. provided the clinical data and critically reviewed the manuscript. C.C. provided the clinical data and critically 
Competing Interest Statement H.Y., G.D., K.G.M., K.R., M.T.C., G.R., and P.V. are employees of GeneDx. Wendy Chung is a consultant to BioReference Laboratories.

Received July 6, 2015; accepted in revised form August 3, 2015. reviewed the manuscript. A.C. provided the clinical data and critically reviewed the manuscript. R.T. provided the clinical data and critically reviewed the manuscript. G.R. analyzed the data and critically reviewed the manuscript. P.V. conceived of the study, analyzed the data, drafted and critically reviewed the manuscript. W.K.C. conceived of the study, analyzed the data, drafted and critically reviewed the manuscript.

\section{Funding}

This work was supported in part by a grant from the Simons Foundation.

\section{REFERENCES}

Afroze B, Chaudhry B. 2013. Genetics of non-syndromic autosomal recessive mental retardation. J Pak Med Assoc 63: 106-110.

Aravind L, Landsman D. 1998. AT-hook motifs identified in a wide variety of DNA-binding proteins. Nucleic Acids Res 26: 4413-4421.

Baker SA, Chen L, Wilkins AD, Yu P, Lichtarge O, Zoghbi HY. 2013. An AT-hook domain in MeCP2 determines the clinical course of Rett syndrome and related disorders. Cell 152: 984-996.

Beaulieu CL, Majewski J, Schwartzentruber J, Samuels ME, Fernandez BA, Bernier FP, Brudno M, Knoppers B, Marcadier J, Dyment D, et al. 2014. FORGE Canada Consortium: outcomes of a 2-year national rare-disease gene-discovery project. Am J Hum Genet 94: 809-817.

Butland SL, Sanders SS, Schmidt ME, Riechers SP, Lin DT, Martin DD, Vaid K, Graham RK, Singaraja RR, Wanker EE, et al. 2014. The palmitoyl acyltransferase HIP14 shares a high proportion of interactors with huntingtin: implications for a role in the pathogenesis of Huntington's disease. Hum Mol Genet 23: 4142-4160.

Chatr-Aryamontri A, Breitkreutz BJ, Oughtred R, Boucher L, Heinicke S, Chen D, Stark C, Breitkreutz A, Kolas N, O'Donnell L, et al. 2015. The BioGRID interaction database: 2015 update. Nucleic Acids Res 43(Database issue): D470-D478.

Coe BP, Witherspoon K, Rosenfeld JA, van Bon BW, Vulto-van Silfhout AT, Bosco P, Friend KL, Baker C, Buono S, Vissers LE, et al. 2014. Refining analyses of copy number variation identifies specific genes associated with developmental delay. Nat Genet 46: 1063-1071.

Cooper GM, Coe BP, Girirajan S, Rosenfeld JA, Vu TH, Baker C, Williams C, Stalker H, Hamid R, Hannig V, et al. 2011. A copy number variation morbidity map of developmental delay. Nat Genet 43: 838-846.

DePristo MA, Banks E, Poplin R, Garimella KV, Maguire JR, Hartl C, Philippakis AA, del Angel G, Rivas MA, Hanna $M$, et al. 2011. A framework for variation discovery and genotyping using next-generation DNA sequencing data. Nat Genet 43: 491-498.

Flore LA, Milunsky JM. 2012. Updates in the genetic evaluation of the child with global developmental delay or intellectual disability. Semin Pediatr Neurol 19: 173-180.

Guipponi M, Santoni FA, Setola V, Gehrig C, Rotharmel M, Cuenca M, Guillin O, Dikeos D, Georgantopoulos G, Papadimitriou G, et al. 2014. Exome sequencing in 53 sporadic cases of schizophrenia identifies 18 putative candidate genes. PLoS One 9: e112745.

Itsara A, Cooper GM, Baker C, Girirajan S, Li J, Absher D, Krauss RM, Myers RM, Ridker PM, Chasman DI, et al. 2009. Population analysis of large copy number variants and hotspots of human genetic disease. Am J Hum Genet 84: 148-161.

Lee HJ, Zheng JJ. 2010. PDZ domains and their binding partners: structure, specificity, and modification. Cell Commun Signal 8: 8.

Leonard H, Wen X. 2002. The epidemiology of mental retardation: challenges and opportunities in the new millennium. Ment Retard Dev Disabil Res Rev 8: 117-134.

Li H, Handsaker B, Wysoker A, Fennell T, Ruan J, Homer N, Marth G, Abecasis G, Durbin R. 2009. The Sequence Alignment/Map format and SAMtools. Bioinformatics 25: 2078-2079.

Lim J, Hao T, Shaw C, Patel AJ, Szabó G, Rual JF, Fisk CJ, Li N, Smolyar A, Hill DE, et al. 2006. A protein-protein interaction network for human inherited ataxias and disorders of Purkinje cell degeneration. Cell 125: 801-814.

McLaren J, Bryson SE. 1987. Review of recent epidemiological studies of mental retardation: prevalence, associated disorders, and etiology. Am J Ment Retard 92: 243-254.

Michelson DJ, Shevell MI, Sherr EH, Moeschler JB, Gropman AL, Ashwal S. 2011. Evidence report: genetic and metabolic testing on children with global developmental delay: report of the Quality Standards 
Subcommittee of the American Academy of Neurology and the Practice Committee of the Child Neurology Society. Neurology 77: 1629-1635.

Musante L, Ropers HH. 2014. Genetics of recessive cognitive disorders. Trends Genet 30: 32-39.

Olah J, Vincze O, Virók D, Simon D, Bozsó Z, Tõkési N, Horváth I, Hlavanda E, Kovács J, Magyar A, et al. 2011. Interactions of pathological hallmark proteins: tubulin polymerization promoting protein/p25, $\beta$-amyloid, and a-synuclein. J Biol Chem 286: 34088-34100.

Petersen MC, Kube DA, Palmer FB. 1998. Classification of developmental delays. Semin Pediatr Neurol 5: 2-14.

Ponten F, Jirstrom K, Uhlen M. 2008. The Human Protein Atlas-a tool for pathology. J Pathol 216: 387-393.

Quintero-Rivera F, Xi QJ, Keppler-Noreuil KM, Lee JH, Higgins AW, Anchan RM, Roberts AE, Seong IS, Fan X, Lage K, et al. 2015. MATR3 disruption in human and mouse associated with bicuspid aortic valve, aortic coarctation and patent ductus arteriosus. Hum Mol Genet 24: 2375-2389.

Rauch A, Hoyer J, Guth S, Zweier C, Kraus C, Becker C, Zenker M, Hüffmeier U, Thiel C, Rüschendorf F, et al. 2006. Diagnostic yield of various genetic approaches in patients with unexplained developmental delay or mental retardation. Am J Med Genet A 140: 2063-2074.

Reeves R, Nissen MS. 1990. The A.T-DNA-binding domain of mammalian high mobility group I chromosomal proteins. A novel peptide motif for recognizing DNA structure. J Biol Chem 265: 8573-8582.

Ropers HH. 2010. Genetics of early onset cognitive impairment. Annu Rev Genomics Hum Genet 11: 161-187.

Schoenberg DR, Maquat LE. 2012. Regulation of cytoplasmic mRNA decay. Nat Rev Genet 13: 246-259.

Seidler U, Singh AK, Cinar A, Chen M, Hillesheim J, Hogema B, Riederer B. 2009. The role of the NHERF family of PDZ scaffolding proteins in the regulation of salt and water transport. Ann NY Acad Sci 1165: 249-260.

Shalaby MA, Hampson L, Oliver A, Hampson I. 2011. Identification of PlexinD1 and AHDC1 as a putative interactors for Tip-1 protein. Genes Genomics 33: 399-405.

Shevell M, Ashwal S, Donley D, Flint J, Gingold M, Hirtz D, Majnemer A, Noetzel M, Sheth RD; Quality Standards Subcommittee of the American Academy of Neurology; Practice Committee of the Child Neurology Society 2003. Practice parameter: evaluation of the child with global developmental delay: report of the Quality Standards Subcommittee of the American Academy of Neurology and The Practice Committee of the Child Neurology Society. Neurology 60: 367-380.

Uhlen M, Fagerberg L, Hallström BM, Lindskog C, Oksvold P, Mardinoglu A, Sivertsson Å, Kampf C, Sjöstedt E, Asplund A, et al. 2015. Proteomics. Tissue-based map of the human proteome. Science 347: 1260419.

Vandamme J, Völkel P, Rosnoblet C, Le Faou P, Angrand PO. 2011. Interaction proteomics analysis of polycomb proteins defines distinct PRC1 complexes in mammalian cells. Mol Cell Proteomics 10: M110.002642.

Veltman JA, Brunner HG. 2012. De novo mutations in human genetic disease. Nat Rev Genet 13: 565-575.

Xia F, Bainbridge MN, Tan TY, Wangler MF, Scheuerle AE, Zackai EH, Harr MH, Sutton VR, Nalam RL, Zhu W, et al. 2014. De novo truncating mutations in AHDC1 in individuals with syndromic expressive language delay, hypotonia, and sleep apnea. Am J Hum Genet 94: 784-789.

Xu X, Pozzo-Miller L. 2013. A novel DNA-binding feature of MeCP2 contributes to Rett syndrome. Front Cell Neurosci 7: 64

Yang Y, Muzny DM, Reid JG, Bainbridge MN, Willis A, Ward PA, Braxton A, Beuten J, Xia F, Niu Z, et al. 2013. Clinical whole-exome sequencing for the diagnosis of Mendelian disorders. N Engl J Med 369: 1502-1511.

Yang Y, Muzny DM, Xia F, Niu Z, Person R, Ding Y, Ward P, Braxton A, Wang M, Buhay C, et al. 2014. Molecular findings among patients referred for clinical whole-exome sequencing. JAMA 312: 1870-1879. 


\section{COLD SPRING HARBOR Molecular Case Studies}

\section{De novo truncating variants in the $A H D C 1$ gene encoding the AT-hook DNA-binding motif-containing protein 1 are associated with intellectual disability and developmental delay}

Hui Yang, Ganka Douglas, Kristin G. Monaghan, et al.

Cold Spring Harb Mol Case Stud 2015, 1: a000562

Access the most recent version at doi: $10.1101 / \mathrm{mcs} . a 000562$

$\underset{\text { Material }}{\operatorname{Supplementary}} \quad{ }_{1}^{\text {http://molecularcasestudies.cshlp.org/content/suppl/2015/09/03/1.1.a000562.DC }}$

References This article cites 37 articles, 4 of which can be accessed free at:

http://molecularcasestudies.cshlp.org/content/1/1/a000562.full.html\#ref-list-1

License This article is distributed under the terms of the Creative Commons Attribution-NonCommercial License, which permits reuse and redistribution, except for commercial purposes, provided that the original author and source are credited.

Email Alerting Receive free email alerts when new articles cite this article - sign up in the box at the Service top right corner of the article or click here. 